\title{
Comparing the Results of Nuclear Supply in North Korea and Libya
}

\author{
Eunji Kim \\ Seoul National University
}

\begin{abstract}
Nuclear supply is a hard topic to study since there are few official documents about it, therefore, researchers should depend on secondary materials. Also, there need to know specific knowledge of technical development in order to realize what really happened among countries. These made this kind of research difficult and that might be why only a handful of studies exist about the issues now. However, if nuclear issue is important, nuclear supply should be tracked. That was the first question that I had in mind when considering nuclear issues. North Korea is one of the countries that have a lot secret in their behaviors, so it would be way more difficult to reveal the process of nuclear supply of that country. Nonetheless, it would be possible to guess the factors which affected the nuclear abandonment of Libya by comparing the case that of North Korea.

North Korea and Libya both the receivers of nuclear technologies in the early phase of nuclear proliferation. Their main suppliers were the same, the Soviet Union and Pakistan. Although the two countries took over some supports from them, the level of support was different and it influenced their result of nuclear weapon development. Libya and North Korea have some things in common in terms of nuclear supply, but other two factors, strategic importance and existence of exchangeable technology, affected the size of external support.
\end{abstract}

Keywords: nuclear supply, Libya, North Korea, strategic importance, exchangeable technology

\section{Introduction}

Nuclear nonproliferation is an important issue that has been handled as a top security problem. In case of the Korean Peninsula, North Korean nuclear program threatens other countries security as well as worsens regional tension. Nuclear proliferation has been dealt with in demand and supply dimensions. Researchers that concentrated on demand side pointed out security, domestic politics, and national heritage are the main reason that countries pursue nuclear weapons. 1 Supply side also pointed out security, economic benefits, and relationship as reasons for nuclear proliferation. 2 The proliferation of nuclear weapons is certainly a situation that was caused by both demand and supply side, but many researches highlighted demand side only.

In some respect, it was natural because it is needed to acquire proper information surrounding nuclear supply in order to supply side reasons, however, there are few materials opened to the public now. Nevertheless, research on supply side is necessary for discovering the reasons of proliferation and preventing it.

Nuclear supply is mainly made by transferring technologies related with nuclear weapons including production of weapon-grade nuclear materials, designing nuclear exploder, constructing facilities for making nuclear weapons. North Korea and Libya both pursued to acquire those technologies from other countries. However, the size and result of technology transfer were different in the two countries. Although the Soviet Union and Pakistan were the main supplier of nuclear technology to Libya and North Korea, Libya did not complete its development of nuclear weapons from the transferred technologies while North Korea succeeded. This difference would result from the different strategic importance and exchangeable technology of the two counties.

This research would reveal the historical process of nuclear supply of Libya and North Korea first, and analyze variables that could affect the difference despite the two countries' common factors.

1 Demand side researches are represented by studies of Scott Sagan(1996); Sonali Singh and Christopher Way(2004); JacqueHymans(2006); Etel Solingen(2007).

2 Supply side researches are represented by studies of Erik Gartzke and Matthew Kroenig(2009); Matthew Kroenig(2009a); Matthew Kroenig(2009b); Matthew Kroenig(2010); Matthew Fuhrmann(2012). 


\section{Nuclear Supply Process of Libya and North Korea}

\subsection{Libya}

Most attempts to have nuclear facilities or weapons began during the Cold War period, when the US tried to persuade its ideological allies with nuclear facilities under the name of 'Atoms for Peace' program, while its counterpart also tried to make friends using the same bait. Under Colonel Muammar Qadhafi's autocratic rule, Libya had sought to win nuclear arms and other weapons of mass destruction for 33 years until it declared the abandonment of its nuclear programs in 2003. Libya's first attempt to win nuclear weapons was in the 1970s. At that time it sought to purchase nuclear weapons directly from China. ${ }^{3}$ After its first attempt failed, Libya tried to cooperate with Pakistan by offering financial aid and supplies of uranium from Niger. It hoped to share Pakistan's nuclear technology. ${ }^{4}$ However, these efforts failed, because Pakistani president Zia ul-Haq denied that Pakistan intended to make a nuclear bomb in 1979. ${ }^{5}$ After Libya ratified the NPT in 1975, Libya and the Soviet Union signed an accord for the establishment of a "center for peaceful purposes in Libya" including a small reactor. ${ }^{6}$ A 10-megawatt research reactor began operating at Tajoura with the help of the Soviet Union in 1979, and it was a rare case of a real nuclear cooperation of Libya. According to the Washington Post, Libya reportedly contracted with the Soviet Union to construct a 440,000-kilowatt nuclear power plant in 1977, but it was not realized. ${ }^{7}$ In the 1980s Libya had tried to establish nuclear relations with Pakistan, India, the Soviet Union, Belgium, Argentina, and Brazil. Although its trials mainly failed, Libya's pursuit of nuclear weapons, however, continued. Libya tried to purchase a plant for manufacturing uranium tetra fluoride, which for producing hexafluoride from the Belgian firm Belgonucleaire. At that time Libya did not have declared nuclear facilities that require uranium tetra fluoride, so a research group suspected that it was for a centrifuge uranium enrichment program underway in Pakistan. ${ }^{8}$ However, the deal was also cancelled.

Libya aimed at drawing nuclear scientists from abroad in the 1990s. The top nuclear official in Moscow, Vyacheslav Rosanov of the I.V. Kurchatov Institute of Atomic Energy, said Libya had offered jobs at its Tajura Nuclear Research Center twice to two Russian nuclear scientists. The first offer was made in the summer of 1991 and the second in late 1991. Both scientists were offered a salary of $\$ 2,000$ a month, but both declined. ${ }^{9}$ According to the Jerusalem Post, Iraqi nuclear scientist Ja'afar Dhia Ja'afar arrived in Libya to lead a group of experts and engineers from Iraqi military industries in installing a small nuclear enrichment kiln in the area of Sidi Abu Zarik, approximately 380 kilometers south of Tripoli. The Iraq-Libya cooperation allegedly began with a secret visit by Ra'ad Id Aldafi, from Libyan military industries, to Baghdad on August 30, 1995. The Jerusalem Post also said that contracts for Iraqi scientists to work in Libya were passed off as contracts for these scientists to lecture in Libyan universities and institutions. ${ }^{10}$ However, not all of the deals for nuclear technology failed. Some deals were made. An IAEA report said Libya could get 20 pre-assembled L-1 centrifuges [an old version of European-designed centrifuges also known as G-1 or P-1] and components for additional 200 L-1 centrifuge from foreign manufacturers, and used the pre-assembled centrifuges to begin installing a completed single centrifuge at Al Hashan. Also, Libya received two L-2 centrifuges which was more advanced than the L-1s allegedly from Pakistan in the late 2000. Libya intended to install a centrifuge plant to make enriched uranium. It started to progressively install nine-machine, 19-machine, and 64-machine L-1 centrifuges into a large hall at Al Hashan. ${ }^{11}$ However, these technologies were not enough for contending Qadhafi's nuclear ambition, because a

\footnotetext{
${ }^{3}$ Rodney W. Jones and Mark G. McDonough, Tracking nuclear proliferation: a guide in maps and charts (Washington D.C.: Carnegie Endowment for International Peace,1998), p. 215

4 Joseph Cirincione, Deadly Arsenals: Nuclear, Biological and Chemical Threats, Revised Edition (Washington D.C.: Carnegie Endowment for International Peace, 2005)

5 Nuclear Threat Initiative (NTI), Libya Nuclear Chronology

6 NTI, Libya Nuclear Chronology

7 NTI, Libya Nuclear Chronology

8 Kenneth Timmerman, Weapons of Mass Destruction: the Cases of Iran, Syria, and Libya (Los Angeles: Simon

Wiesenthal Center, August 1992), p. 89

9 Kenneth Timmerman(1992), p. 90

10 NTI, Libya Nuclear Chronology

11 Report by the General Director, "Implementation of the NPT Safeguards Agreement of the Socialist People's Libyan Arab Jamahiriya," (International Atomic Energy Agency, GOV/2004/12, 20 February 2004), p. 5.
} 
CIA report revealed that Libya still needed significant foreign assistance to advance nuclear weapons. ${ }^{12}$ Although Libya promised to give up its nuclear weapons program in 2003, there had been more efforts to get a sensitive nuclear technology from abroad before it abandoned the program. A CIA report said that, "in 2001, Libya and other countries reportedly used their secret services to try to obtain technical information on the development of weapons of mass destruction, including nuclear weapons." The report cited Tripoli's attempts to buy a nuclear reactor from Russia and efforts to secure Moscow's assistance in developing the Tajura nuclear research center. ${ }^{13}$ In addition, thousands of centrifuge parts used to enrich uranium were caught by US and British intelligence on their way to Tripoli. The equipment found aboard German-owned freighter BBC China were a proof of Libya's clandestine nuclear weapons program. Authorities announced that the shipment came from a Persian Gulf port, but they did not name the country of origin. Other reports insisted that the centrifuge parts were being sent from Malaysia to Libya, via the port city of Dubai in the United Arab Emirates. ${ }^{14}$

Libya had tried to develop nuclear weapons for 30 years before it promised to abandon its nuclear program, but reportedly the level of nuclear technology of the country was in an elementary state. Some thought that Libya revealed its intention to abandon nuclear weapon program in the late phase of its development rather that after it succeeded it. It was because Libya failed to attain enough technologies and money for nuclear weapons.

\subsection{North Korea}

North Korea had conducted three nuclear tests already, and launched missiles that could carry nuclear warheads. These facts support the statement that North Korea possesses full nuclear fuel cycle capabilities, including a presumed basic capability to enrich uranium, although the functionality of its centrifuges has not yet been substantiated to the outside world. North Korea planned to build a small light water reactor (LWR) at Yongbyon in $2011^{15}$, and recently seemed to resume its operation. Even if it seems that North Korea attained nuclear technologies by itself, there have been some nuclear supply processes until the state has this level of technology. North Korea's nuclear ambition started right after the Korean War. Pyongyang signed the founding charter of the Soviet Union's Joint Institute for Nuclear Research in February 1956, and began to send scientists and technicians to the USSR for training shortly thereafter. In 1959, North Korea and the Soviet Union signed an agreement on the peaceful use of nuclear energy that included a provision for Soviet help to establish a nuclear research complex in Yongbyon, North Pyongan Province. 16

In the 1960s, the Soviet Union supported North Korea in order to establish the Yongbyon Nuclear Research Center, which included the installation of a Soviet IRT-2000 nuclear research reactor and associated facilities. North Korea used this small research reactor to produce radioisotopes and to train personnel. ${ }^{17}$ From the 1970 s to 1993 North Korea mainly made indigenous efforts to develop nuclear weapons by founding educational and research institutions, but it did acquire plutonium reprocessing technology from the Soviet Union in the 1970s. ${ }^{18}$ It is unsure which level of nuclear weapon technology North Korea has, however, many think that it has technologies of making nuclear warhead using highly enriched uranium (HEU), and these were from Pakistan.

Nuclear connection between North Korea and Pakistan began in the 1990s. Pakistani Prime Minister Benazir Bhutto visited Pyongyang in December 1993 and nuclear relations between the North and A. Q. Khan network was initiated during Bhutto' term according to a CIA report. A five-year-long German intelligence investigation conducted from 1985 to 1990 concluded that Iraq, and possibly Iran and North Korea obtained uranium melting information from Pakistan in the late 1980s. ${ }^{19}$ U.S. intelligence sources also believed that technicians employed

12 NTI, Libya Nuclear Chronology

13 NTI, Libya Nuclear Chronology

14 Rupert Cornwell, "Intercepted Shipment was Key to Libya Deal," Financial Times Global News Wire, 2 January 2004

15 "North Korea Makes Significant Progress in Building New Experimental Light Water Reactor (ELWR)," 38 North, (14 November 2011), http://38north.org.

16 NTI, Country Profiles, North Korea

17 Gregory Karouv, "A Technical History of Soviet-North Korean Nuclear Relations," in James Clay Moltz and Alexandre Y. Mansourov, eds., The North Korean Nuclear Program: Security, Strategy, and New Perspectives from Russia (New

York: Routledge, 2000), p. 17

18 NTI, Country Profiles, North Korea

19 “Agencies Trace Some Iraqi URENCO Know-How to Pakistan Re-Export,” Nucleonics Week, November 28, 1991, pp. $1,7-8$. 
by Leybold AG were involved in transferring equipment and information to North Korea. One or two such technicians were in North Korea in 1989 and another Leybold employee reportedly was seen there in 1990. Subsidiaries of Leybold AG were also involved in exporting centrifuge-related welding equipment to Iraq in the late 1980s. During the 1990s, North Korea made a big deal with the South and the US respectively, named North-South Joint Declaration in the Denuclearization of the Korean Peninsula in 1992 and the Agreed Framework in 1994. The Agreed Framework let North Korea return to NPT and promise to freeze nuclear facilities in exchange for 500 thousand tons of heavy fuel oil annually from the US before the Korean Peninsula Energy Development Organization (KEDO) completed its construction of two right water reactor (LWR) in North Korea. However, the Agreed Framework was violated in 2002 and there began suspicions of nuclear ties between North Korea and Pakistan. On February 24, 2004, CIA Director George Tenet told the Senate Select Committee on Intelligence that "We ...believe Pyongyang is pursuing a production scale uranium enrichment program based on technology provided by AQ Khan, which would give North Korea an alternative route to nuclear weapons." ${ }^{20}$ Even though there is currently no detailed, unclassified information on the assistance of Pakistan to North Korea, one media report, citing Western officials, said the aid included a complete design package for a centrifuge rotor assembly, while a Japanese report stated that Pakistan had exported actual centrifuge rotors $(2,000-3,000)$ to North Korea. It attempted to obtain materials from China, Japan, Pakistan, Russia, and Europe, but Pakistan provided most of the assistance related to the rotors. A Pakistani official involved in Khan's investigation reportedly said North Korea ordered P-1 centrifuge components from 1997 to 2000. In his September 2006 memoir, Pakistani President Musharraf stated that he believes that Khan sent some of "Pakistan's most technologically advanced nuclear centrifuges. ${ }^{21}$

Pakistan's assistance has impacted North Korea to develop uranium enrichment technology. The ability to produce fissile material might not be important to North Korea since it left the NPT in 2003. Nonetheless, such a program may make the North Korean arsenal less vulnerable to possible military strikes because centrifuge enrichment facilities are hard to detect. Also, the production of HEU, together with plutonium production, could give the North Koreans the option of producing more sophisticated nuclear weapons, for example, using composite pits or boosted fission techniques. ${ }^{22}$

\section{Variables Affecting the Different Nuclear Supply of North Korea and Libya}

North Korea and Libya have things in common regarding the process of nuclear supply. First, the two countries were ruled by dictators. There were Qadhafi and Kim Jong Il in the countries. The fact that they were ruled by dictators affected the closeness of them and it made difficult to reveal the process of nuclear development including for the peaceful use. Second, they were mainly supported by the Soviet Union and Pakistan. In the 1950s there was a competition between the US and the Soviet Union concerning nuclear supply. The US provided nuclear technologies to its allies such as western European countries or South Korea for peaceful use. However, North Korea and Libya could not be the subject of the program and their main nuclear supplier was the Soviet Union. Later, it was replaced by Pakistan in which there was a large nuclear proliferation group led by A. Q. Khan. Third, both of the countries eagerly pursued nuclear weapons. They started their efforts to develop nuclear weapons in an early stage and continuously sought to have nuclear technologies. On the one hand, they pursued nuclear weapons for a security reason because of the existence of enemies near them, Israel to Libya and South Korea and the US to North Korea. On the other hand, they hoped to utilize nuclear weapons as a means to negotiate with their counterparts as did North Korea in 1994. Lastly, they were under pressure from the western society due to their intention to nuclear development. They both have an experience of facing economic sanctions from the US. Western countries including the US and Israel did not want the countries to possess nuclear weapons, so strong sanctions were imposed to the states.

However, even though they share these things, the result of the nuclear supply was different. While North Korea earned enough supports from outside, Libya did not get enough technologies to develop its weapons. This is because some factors affect the nuclear supply of them differently.

20 Sharon A Squassoni, "Weapons of mass destruction: trade between north Korean and Pakistan", CRS Report for Congress (November 28, 2006), p.9

21 Squassoni (2006), p. 10

22 Squassoni (2006), p. 12 


\subsection{Strategic Importance}

Libya and North Korea were socialist countries. Under Qadhafi's rule Libya nationalized oil producing regions and spent money from it in order to enhance social welfare. Qadhafi also redistributed lands and meddled in most macroeconomic sectors. Although some reasons changed him as an Islamic extremist, Qadhafi had pursued socialist values right after he succeeded in the coup. Because the Soviet Union supplied nuclear technologies only to socialist countries, Libya and North Korea could earn the technologies from the Soviet Union in the first phase of the proliferation. However, the importance of the countries was not same to the Soviet Union. While Libya was far from the country, North Korea shared borderlines with it. Also, there was a stark ideological competition in the Northeast Asia, but not in the African continent at that time.

North Korea was one of the most significant regions to the Soviet Union for the ideological competition and that might affect the level of Soviet's support for nuclear supply. Libya, of course, did get assistances from the Soviet Union in the process of constructing 10-megawatt research reactor at Tajoura in 1979, but their next contract to build 44-megawatt reactor was cancelled because of the Soviet Union. Whereas, North Korea signed the founding charter of the Soviet Union's Joint Institute for Nuclear Research in February 1956, and began to send scientists and technicians to the USSR for training shortly thereafter. In 1959, North Korea and the Soviet Union signed an agreement on the peaceful use of nuclear energy that included a provision for Soviet help to establish a nuclear research complex in Yongbyon, North Pyongan Province. In the 1960s, the Soviet Union supported North Korea in order to establish the Yongbyon Nuclear Research Center, which included the installation of a Soviet IRT-2000 nuclear research reactor and associated facilities. Thanks to the help of the USSR, North Korea could create a basis for its indigenous nuclear development in the 1970s.

Concerning nuclear supply, some countries decided the destination of their technologies whether they have common enemies or not. For instance, France made a contract for nuclear cooperation with Israel in 1957 and helped Israel to construct research reactors at Dimona and to succeed in nuclear test in 1966. The main motive was the existence of common enemy. There was hostility in both France and Israel toward the Nasser administration. France complained about Nasser's assistance for Algeria in the process of the Algerian War and Israel was not satisfied with nationalization of Suez Canal by Egypt. This condition strongly affected France's choice of Israel as a partner to support nuclear technologies.23

Pakistan's support for nuclear technologies toward North Korea could be regarded in this respect. Although Pakistan and North Korea did not directly share common hostility toward a country, North Korea was influenced through China. Pakistan and China have common problem of border issues with India. Pakistan had waged wars three times against India because of the Kashmir region and China also fight against India for the land issues. This made China passed over nuclear technologies to Pakistan after India succeeded in nuclear test called Smiling Buddha and North Korea was affected a de facto alliance between China and Pakistan.

Strategic importance might be related with China's decision not to provide nuclear weapons to Libya. China was asked to directly sell nuclear weapons to Libya in the 1970s, but it was rebuffed by China. The direct deal of nuclear weapons was highly dangerous and it was the reason for the China's refusal, however, China gave little nuclear help to Libya after that.

\subsection{Existence of exchangeable technology}

Libya and North Korea seemed to have different approaches toward the way for earning nuclear technologies. Above of all, Libya tried to gain the technologies from other countries by providing economic benefits. Deals with Pakistan could be an instance. After Libya failed to buy nuclear weapons from China, Libya tried to cooperate with Pakistan by offering financial aid and supplies of uranium from Niger. It hoped to share Pakistan's nuclear technology. However, these efforts went no avail, because Pakistani president Zia ul-Haq denied that Pakistan intended to make a nuclear bomb in 1979. Libya also provided Pakistan with aluminum for building a reactor which it bought from some other country. It was because Libya wanted to take over high level of nuclear technologies form Pakistan after the country made trials by itself. Some deals were made but nuclear technologies that Libya got from Pakistan was not enough for completing nuclear weapon program, so it failed to possess the weapon.

23 Kroenig(2010) 
On the contrary, North Korea suggested technological exchange instead of financial aid. There was an indigenous development period in North Korea's nuclear development process, and it might have enhanced the level of its technology. North Korea actually have made a lot efforts to be a military strong country since the Korean War, therefore it could have its original technologies in some fields. North Korea has developed in various fields such as missile, satellite, biological or chemical weapons, and these were needed by other countries. For example, technology of North Korea's first ballistic missile, rodong-1, was used in Pakistan.

Pakistan succeeded in nuclear test in the 1960s, but it still needed missile technology in order to deliver the weapons. North Korea and Pakistan made a deal of exchanging their technologies and it rendered Pakistan not to unilaterally violate contract as in the case with Libya. As a result, Pakistan continuously has maintained a transactional relationship with North Korea and it would affect the level of nuclear supply Pakistan provided.

\section{Conclusion}

Nuclear supply is a hard topic to study since there are few official documents about it, therefore, researchers should depend on secondary materials. Also, there need to know specific knowledge of technical development in order to realize what really happened among countries. These made this kind of research difficult and that might be why only a handful of studies exist about the issues now. However, if nuclear issue is important, nuclear supply should be tracked. That was the first question that I had in mind when considering nuclear issues. North Korea is one of the countries that have a lot secret in their behaviors, so it would be way more difficult to reveal the process of nuclear supply of that country. Nonetheless, it would be possible to guess the factors which affected the nuclear abandonment of Libya by comparing the case that of North Korea.

North Korea and Libya both the receivers of nuclear technologies in the early phase of nuclear proliferation. Their main suppliers were the same, the Soviet Union and Pakistan. Although the two countries took over some supports from them, the level of support was different and it influenced their result of nuclear weapon development. Libya and North Korea have some things in common in terms of nuclear supply, but other two factors, strategic importance and existence of exchangeable technology, affected the size of external support.

\section{References}

[1] Hymans, Jacques. 2006. The psychology of nuclear proliferation: Identity, emotions, and foreign policy. Cambridge: Cambridge University Press.

http://dx.doi.org/10.1017/CBO9780511491412

[2] Sagan, Scott. 1996/97. "Why do states build nuclear weapons? Three models in search of a bomb." International Security 21 (3), pp: 54-86.

http://dx.doi.org/10.2307/2539273

[3] Singh, Sonali, and Christopher Way. 2004. "The correlates of nuclear proliferation: A quantitative test." Journal of Conflict Resolution, 48, pp:859-85.

http://dx.doi.org/10.1177/0022002704269655

[4] Solingen, Etel. 2007. Nuclear logics: Contrasting paths in East Asia and the Middle East. Princeton, NJ: Princeton University Press.

[5] Gartzke, Erik and Matthew Kroenig. 2009. "A strategic approach to nuclear proliferation." The Journal of Conflict Resolution, Vol. 53, No. 2, (APRIL 2009), pp. 151-160.

[6] Kroenig, Matthew.2009a. "Importing the Bomb," Journal of Conflict Resolution, Vol.53.

http://dx.doi.org/10.1177/0022002708330287

[7] Kroenig, Matthew.2009b. "Exporting the Bomb: Why States Provide Sensitive Nuclear Assistance," American Political Science Review, Vol. 103.

[8] 2010. Exporting the Bomb, New York: Cornell University Press.

[9] Fuhrmann, Matthew. 2012. Atomic Assistance: how "atoms for peace" programs cause nuclear insecurity, New York: Cornell University

[10] Jones, W Rodney and Mark G. McDonough. 1998. Tracking nuclear proliferation: a guide in maps and charts, Washington DC: Carnegie Endowment for International Peace.

[11] Cirincione, Joseph . 2005. Deadly Arsenals: Nuclear, Biological and Chemical Threats, Revised Edition, Washington DC: Carnegie Endowment for International Peace. 
[12] Timmerman, Kenneth. 1992. Weapons of Mass Destruction: the Cases of Iran, Syria, and Libya, Los Angeles: Simon Wiesenthal Center.

[13] Karouv, Gregory. 2000. "A Technical History of Soviet-North Korean Nuclear Relations," in James Clay Moltz and Alexandre Y. Mansourov, eds., The North Korean Nuclear Program: Security, Strategy, and New Perspectives from Russia, New York: Routledge.

[14] Squassoni A. Sharon. 2006. "Weapons of mass destruction: trade between North Korea and Pakistan", CRS Report for Congress

[15] Report by the General Director, "Implementation of the NPT Safeguards Agreement of the Socialist People's Libyan Arab Jamahiriya," (International Atomic Energy Agency, GOV/2004/12, 20 February 2004)

[16] 38 North, http://38north.org.

[17] Nuclear Threat Initiative (NTI), http://www.nti.org/ 